\title{
A Case of Dyskinesia Presenting as Belly Dancer's Syndrome
}

\section{Chang-Beom Bae, Sang-Bub Lee and Oh-Dae Kwon*}

Department of Neurology, Daegu Catholic University Medical Center School of Medicine, Catholic University of Daegu, Korea

*Corresponding author: Oh-Dae Kwon, Department of Neurology, Daegu Catholic University Medical Center School of Medicine, Catholic University of Daegu, Korea, Tel: +82.53-650-4298; Fax: +82.53-654-9786; E-mail: dolbaeke@cu.ac.kr

Received date: July 01, 2017; Accepted date: July 03, 2017; Published date: July 07, 2017

Citation: Bae CB, Lee SB, Kwon OD (2017) A Case of Dyskinesia Presenting as Belly Dancer's Syndrome. Dual Diagn Open Acc Vol.2 No.2: 33.

Copyright: (C2017 Bae CB, et al. This is an open-access article distributed under the terms of the Creative Commons Attribution License, which permits unrestricted use, distribution, and reproduction in any medium, provided the original author and source are credited.

\section{Clinical Image}

Belly dancer's syndrome, also known as diaphragmatic flutter, is a rare condition consisting of involuntary, repetitive contractions of the diaphragm [1].

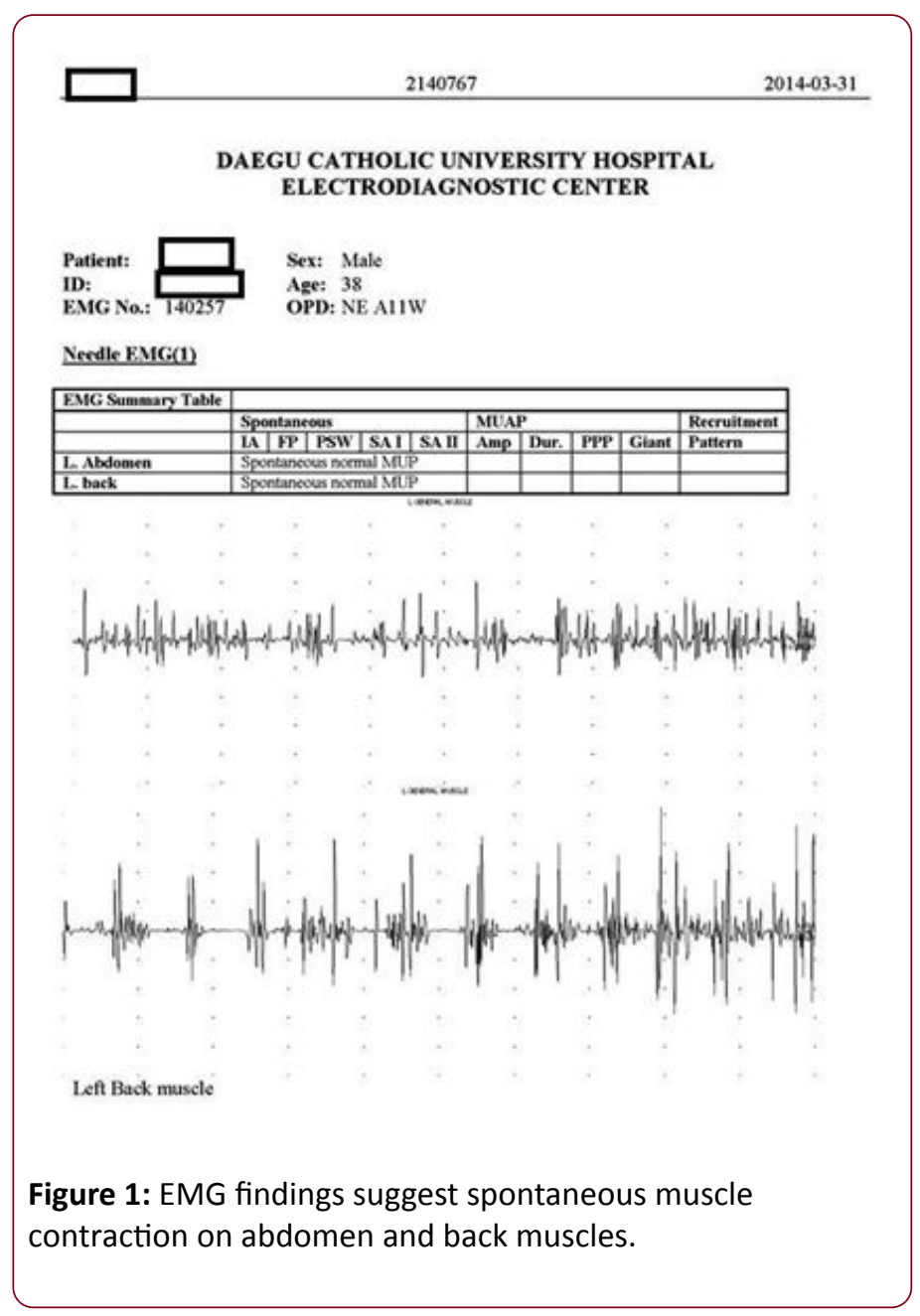

Patients with this syndrome usually have a history of trauma or surgery associated with abdominal pain, which is localized where trauma had occurred [2-4]. Fluoroscopy and electromyography are the most advantageous methods of diagnosis $[5,6]$. The patient is 38-year-old man presented with involuntary movement of abdominal muscles for 4 months. The involuntary movement of abdominal muscles developed during sitting or standing position. L-spine MRI revealed L5-S1 disc herniation. Nerve conduction studies showed spontaneous muscle contractions of abdomen and back (Figure 1). The symptom improved partially with introduction of clonazepam (0.5 mg/day).

\section{Reference}

1. Amin OSM, Abdulkarim QH, Shaikhani M (2012) Intermittent bursts of abdominal wall jerky movements: belly dancer's syndrome?. BMJ Case Reports 007393.

2. Kim JY, Kim JE, Baek BS, Hong C, Park SP, et al. (1998) Unusual focal dyskinesia: the ears and abdomen. J Korean Neurol Assoc 16: 706-708.

3. Kobayashi I, Tazaki G, Hayama N, Kondo T (2004) A case of the diaphragmatic flutter with an electromyographic study of the respiratory muscles. Tokai J Exp Clin Med 29: 151-154.

4. Stefano T, Domenico I, Giampietro Z (2007) Belly dancer's myoclonus and chronic abdominal pain: pain-related dysinhibition of a spinal cord central pattern generator? Parkinsonism and related disorders 13: 317-320.

5. Young CR, Clapp L, Salcedo V, Whitelock WL (1995) Diaphragmatic myoclonus: diagnosis by fluoroscopy and electromyography with response to phenytoin. South Med J 88: $1270-1273$.

6. Samardhi H, Radford D, Fong K (2010) Leeuwenhoek's disease: diaphragmatic flutter in a cardiac patient. Cardiol Young 20: 334-336. 